\title{
FREUD: O ALÉM DO HOMEM E O PATRIARCA DA HORDA PRIMEVA ${ }^{1,2}$
}

\author{
Eduardo Ribeiro da Fonseca (PUC-PR) ${ }^{3}$
}

eduardorfonseca@uol.com.br

Resumo: As relações de Freud com a noção de além-do-homem evidenciam um duplo movimento, caso consideremos a satisfação direta dos Triebe em contraste com a possibilidade do refinamento dos alvos pulsionais. Por um lado, o psicanalista aceita a ideia de Nietzsche de que a sublimação é justamente o meio pelo qual se dá esse refinamento transformador dos alvos dos impulsos, mas reafirma simultaneamente a ideia schopenhaueriana de que o sofrimento é o fundo de toda a vida, já que a tensão constante do impulso é justamente o fenômeno que nos tensiona e nos impele adiante: É da diferença entre o prazer efetivo obtido pela satisfação em relação ao prazer esperado que surge o fator que impele (treibende). Este não permite que o organismo estacione em nenhuma das formas de satisfação anteriormente estabelecidas, mas, ao contrário, fará com que esse organismo, em seu contexto psíquico,reivindique um estado de satisfação profunda, que é, no entanto, impedida tanto pela força das resistências que o processo de recalcamento ainda mantém ativas, quanto pelas dificuldades inerentes ao convívio humano e ao conflito entre desejos e capacidades.

Palavras-chave: Desejo; impulso; vontade de poder; horda.

Em Psicologia de massas e análise do eu (MassenpsychologieundIch-Analyse, 1921), escrito por Freud, podemos considerar

\footnotetext{
${ }^{1}$ Recebido: 14-10-2014/Aceito: 25-02-2016/Publicado on-line: 06-03-2016.

${ }^{2} \mathrm{O}$ presente artigo continua uma série de discussões acerca da noção de psicanalítica de Trieb iniciada com o livro Psiquismo e Vida: Sobre a noção de Trieb nas obras de Freud, Schopenhauer e Nietzsche.

${ }^{3}$ Eduardo Ribeiro da Fonseca é Professor de Filosofia e Ética do Departamento de Filosofia da Pontifícia Universidade Católica do Paraná, Curitiba, PR, Brasil.
} 
uma importante questão filosófica abordada por Friedrich Nietzsche em diversos pontos de sua obra filosófica, e em especial, no livro Assim falou Zaratustra: um livro para todos e para ninguém (Also Sprach Zarathustra: ein Buch für Alleund Keinen, 1883-5). Toda expectativa para o porvir humano recebe necessariamente a marca da suposição e da possibilidade, de um querer ser de certa maneira e em $\mathrm{Ni}$ etzsche isto é tratado de modo essencialmente poético. No texto sobre as novas e velhas tábuas, que é exemplar neste sentido, o homem aparece como "algo que tem de ser superado" 4 e "um caminho para novas auroras" 5 . Ali, o homem em sua configuração atual surge como um "grande meio-dia”, como um ponto de viragem para um porvir que precisaria ser inventado e para isto o próprio homem necessitaria ser recriado a partir de seu próprio desejo. Para tanto, Zaratustra ensina a "redimir criando". Se a Humanidade como é conhecida é algo que deveria ser abandonado em prol de algo melhor, de que modo aparece a possibilidade de superação do tipo humano? Há algo de enigma em sua formulação. Ele escreve que muitos podem "mandar em si", mas ainda falta muito "para que também se obedeçam" ${ }^{6}$. Certamente as manhas e manhãs do inconsciente falam alto nessa consideração do desejo de potência e do estabelecimento de novas configurações humanas para além das atuais. Podemos entender esta questão dentro de um contexto não apenas especulativo, mas também do ponto de vista de uma semente plantada na imaginação dos leitores, como uma forma de estimular o desejo de superação das

\footnotetext{
${ }^{4}$ NIETZSCHE, F. Assim Falou Zaratustra. In: Obras Incompletas, § 3, Das velhas e novas tábuas, tradução de Rubens Rodrigues Torres Filho, p. 250.

${ }^{5}$ Idem ibidem.

${ }^{6}$ Ibidem, § 4, p. 251.
} 
condições atuais do ser e do existir. O Zaratustra como um todo parece ter essencialmente este caráter de provocação ao leitor. Uma provocação antecipatória em relação ao que veio a ser a psicanálise do ponto de vista da mudança de meios e fins pulsionais, já que, como escreve Nietzsche no mesmo livro, para novas canções são necessárias novas liras?

Esta é uma belíssima questão para filósofos e psicanalistas, tendo em vista que Freud, admirador de Nietzsche como psicólogo, recoloca a questão dos fins e meios de modo aparentemente oposto.

\section{O FUTURO ESTAVA NO PASSADO?}

Em Freud ocorre algo surpreendente para quem estivesse até então seguindo o raciocínio nietzschiano. No texto do criador da psicanálise, a personagem mítica do além-dohomem (Übermensch) ${ }^{7}$ é situada cronologicamente no passado, na posição de patriarca da horda primitiva (Urhorde), pois unicamente ele apresentaria então uma psicologia individual (Individual psychologie), que vinha associada ao seu poder inconteste, enquanto para o grupo restava apenas a obediência hipnótica diante de um domínio autoritário e absoluto, à maneira do que em geral ocorre entre mamíferos. Tal obediência estaria baseada, como em Nietzsche,

\footnotetext{
${ }^{7}$ Segundo Rubens Rodrigues Torres Filho, em sua nota ao termo nas Obras Incompletas, o "Übermensch"significa "aquele que transpõe os limites do humano", e, por falta de um termo adequado em português, o tradutor se apoia nas pistas fornecidas pelo próprio autor na sua contextualização do termo, entendido como "travessia, passar, atravessar". "Über" (sobre, por sobre, para além) se referiria a esse contexto de "work in progress" que, para o tradutor, resulta da leitura do sentido do prefixo e do termo "Übermensch" no texto do Zaratustra. Portanto, Torres Filho recusou a tradução como "Super-homem" que, de qualquer modo, está ligada a uma tradição de leituras que desconsideram esse caráter de ponte entre uma coisa e outra, entre o homem (uma corda atada entre o animal e o além-do-homem, uma corda sobre um abismo, conforme o Prefácio de Zaratustra, § 4) e aquilo em que ele pode ser transmutado (algo que depende de uma travessia, de uma passagem, de uma viragem).
} 
num "Herdentrieb" 8 , um "impulso de rebanho", uma pulsão gregária e que, por isto, tenderia ao uníssono, à obediência e ao ressentimento por parte dos outros membros do grupo. $O$ patriarca seria então o indivíduo em sua definição inaugural, o indivíduo originário e as camadas de memória ligadas à sua existência formadas no psiquismo da horda, ao longo de gerações subsequentes, teriam associado a ele impressionantes características divinas. "Nos primórdios da história humana o patriarca da horda primitiva foi o alémdo-homem, cujo aparecimento esperava Nietzsche para o distante futuro" 9 . As características desse senhor patriarcal são definidas do seguinte modo: "Ele não necessita amar a ninguém, pode tornar-se dono e senhor e, sendo totalmente narcisista, acha-se seguro de si mesmo e goza de completa independência” ${ }^{10}$. Freud expõe as dificuldades inerentes ao fato de que tal indivíduo, em sua total independência, não precisa se identificar a ninguém, não necessita de compaixão: "Sabemos que o narcisismo limita o amor, e poderíamos demonstrar que atuando assim, constituiu-se como um efeito do fator cultural" ${ }^{11}$. Tal fator civilizatório resulta do fato de que o pai da horda primitiva não era imortal, como depois chegou a ser por divinização, e, desse modo, alguém teve que ocupar o seu lugar, o que sugere a hipótese de que deve existir uma possibilidade de transformar a psicologia de grupo em psicologia individual, o que é

\footnotetext{
${ }^{8}$ FREUD, S. Das Werk, Massen-Psychologie und Ich-Analyse, IX, Der Herdentrieb, p. 109.Freud fala também em „sozialenTriebes“, „ herdinstinct“, „group mind“. Note-se que o termo „instinct“ colocado com a letra "c" indica o inglês e pode tanto sugerir uma possibilidade para a tradução inglesa da palavra "Trieb" como uma indicação da raiz instintiva e simplesmente animal deste impulso humano.

${ }^{9}$ Ibidem, X, p. 116.

${ }^{10}$ Idem ibidem.

${ }^{11}$ Idem ibidem.
} 
reforçado pela observação natural, pois, de modo análogo, o mesmo ocorre entre formigas e abelhas, que em caso de necessidade fazem surgir dentre as larvas uma rainha no lugar de uma operária. Do ponto de vista humano, tal transformação encontra sua justificativa nos modos de satisfação dos impulsos sexuais. Segundo Freud, o pai primitivo impedia que seus filhos obtivessem a satisfação de suas tendências sexuais diretas, lhes impunha a abstinência e, por conseguinte, a título de derivação, impunha-lhes também o estabelecimento de laços afetivos que os ligavam à psicologia coletiva. Em última análise, esta psicologia de grupo não seria mais do que um produto de seus zelos sexuais e de sua intolerância. A hipótese sobre o parricídio resultaria, de acordo com o psicanalista, da consideração de que filhos expulsos da horda passariam da identificação recíproca à eleição de objeto homossexual, conquistando assim sua liberdade, o que lhes permitiu matar o pai. De acordo com a hipótese do psicanalista vienense, todas as organizações sociais atuais derivariam desse protótipo primitivo que por um lado se baseia no amor e poder paternos, e, por outro, na culpa pelo seu assassinato. Como? O parricídio como injunção emancipatória? Não era para ser uma simples metáfora? De acordo com Freud, assim como em Nietzsche, nos primórdios da Humanidade, as coisas se resolviam de um modo essencialmente concreto e apenas no decorrer do tempo, com o alargamento e o aprofundamento da consciência humana, tudo ficou mais sutil e o parricídio adquiriu uma conotação simbólica, ritualizada e, por fim, tornou-se uma metáfora da emancipação do indivíduo de sua origem.

Em Moisés e o monoteísmo repete-se o mesmo esquema, dessa vez associado à figura do fundador da cultura judaica e ao monoteísmo, uma cultura religiosa que, segundo 
Freud, foi expatriada do Egito, onde não vingou: "Se Moisés era egípcio e se transmitiu aos judeus sua religião, esta era a de Akhnaton, a religião de Aton" ${ }^{12}$. Ao se impor entre os judeus, o monoteísmo impôs severas restrições à liberdade humana. A angústia e o ressentimento que se originam dessas relações definiram as características da civilização ocidental através de um estilo de recalque, que, para Freud, expressam uma forma de psicologia individual e uma forma de psicologia de grupo, que nos termos nietzschianos é traduzido pelas noções de psicologia do senhor e psicologia do escravo, extensamente analisadas na Genealogia da moral. Por outro lado, ainda no Zaratustra, a vontade de potência está ao fundo de todas essas manifestações que engendram a cultura: "Onde encontrei vida, ali encontrei a vontade de potência; e até mesmo na vontade daquele que serve encontrei vontade de ser senhor" ${ }^{13}$.

A visão freudiana do além-do-homem realmente contraria a forma como o autor do Zaratustra articula o conceito? Em Nietzsche as resistências são pensadas como fenômenos de proporção entre impulsos (Triebe) e as restrições são necessárias para a geração do tipo excepcional ${ }^{14}$, exatamente como o psicanalista vienense escreve acerca do recalque em sua função estrutural e estruturante para o sujeito; mas, não é que a civilização se origine do recalque em si, mas sim da sublimação e da sintomatologia que dele resultam, por força do retorno do recalcado. Em Nietzsche, as oposições

\footnotetext{
${ }^{12}$ Ibidem, Der mann Moses und die monotheistiche Religion, 3, p. 475.

${ }^{13}$ NIETZSCHE, F. Assim Falou Zaratustra. In: Obras Incompletas, Da superação de si, tradução de Rubens Rodrigues, p. 238.

${ }^{14} \mathrm{Na}$ Genealogia da Moral, conforme a tradução de Paulo César de Souza, Nietzsche se refere a "impulsos reguladores inconscientemente certeiros (ou que guiam com segurança)" [die regulierendenunbewußt-sicherführenden Triebe]. Isto sugere uma economia psíquica ao fundo da consciência, tal como concebida por Freud.
} 
mútuas são entendidas como necessárias e até desejadas para afirmação da potência orgânica em geral e fisiopsicológica em particular. $\mathrm{O}$ próprio impulso deseja uma certa resistência para a sua melhor satisfação. De seu ponto de vista, caso a afirmação unilateral do indivíduo equivalesse de algum modo à afirmação de um único impulso, isto seria apenas sintomático, pois eliminaria o caráter do jogo entre potências, o fort-da ou chiaroscuro das forças em jogo no íntimo do peito. Esse é um elemento importante e ressaltado na obra póstuma, em função da luta dos impulsos pela satisfação nos objetos do mundo, o que implica no seu regime específico de "alimentação", sua eventual inanição, seus conflitos e seus amálgamas em torno de uma experiência concreta possibilitada pela vida.

Do mesmo modo, Freud parece interpretar a existência plausível do além-do-homem sem esse tipo de nuance que remete à perspectiva filosófica da mesma noção em Nietzsche. Isto talvez possa ser remetido ao excesso de proximidade histórica entre eles com tudo o que isto implica, especialmente a recepção da sua contemporaneidade em relação ao filósofo, que o confundia então com um filósofo do totalitarismo. Sendo assim, tal interpretação ignorou o elogio de Nietzsche ao mundo grego, exatamente pela visão de que ali é privilegiada: a disputa e não a vitória a qualquer preço (a vontade de potência não se apresenta exclusivamente na hegemonia paranóica de um ditador qualquer, mas sim na permanente disputa das forças possíveis, as quais resultam de interpretações do mundo efetivo). O herói grego é leal ao espírito da luta, o que exige que o adversário não seja suprimido, mas sim valorizado. Tanto é assim, que o adoecimento é entendido no contexto do predomínio excessivo de tendências hegemônicas. É só nos 
estados em que a relação entre grupos de impulsos se coloca em desproporção é que surge o aspecto doentio, o que é um correlato do modo como Nietzsche interpreta a doença orgânica.

No entanto, desde a consideração do impulso apolíneo e do impulso socrático não se pensa propriamente em uma tendência primordial para a morte, nos moldes de Freud. Em Nietzsche, tal tendência aparece como uma ação renovadora do impulso à potência a partir de um estado de decadência anterior, como no caso de Sócrates, ou como elemento constitutivo de um processo de alteração no equilíbrio de forças, como no caso de suas teses sobre a Vontade de poder. A ordem subjacente à descrição do impulso socrático é a do excesso, da unilateralidade, exatamente como aparece o além-do-homem na descrição de Freud. Tal impulso quer se tornar instinto, e, de coisa secundária, transformar-se em coisa primária. Ele não admite alvos concorrentes e a dialética é a arma utilizada para a sua afirmação exclusiva.

Nietzsche toma-se de certo espanto diante dessa curiosa tentativa de reversão do impulso em instinto, tanto que este último termo adquire na sua obra um caráter eminentemente irônico. Para Almeida (2005), a noção de instinto é usada contra Sócrates, no capítulo 13 de O nascimento da Tragédia, justamente porque este filósofo condena o instinto, quando, por exemplo, fala de práticas exercidas "apenas instintivamente". Esta é, pelo contrário, justamente a forma como Nietzsche enxerga o próprio socratismo, ou seja, como um movimento do pensamento em que predomina cega e rigidamente a racionalidade como se ela mesma fosse um instinto. Nesse sentido, "o termo adquire um caráter nitidamente pejorativo, pois não se trata do instinto enquanto 
expressão das forças artísticas da natureza que apontam para a exuberância, a fertilidade e a afirmação da vida, mas, antes, de algo estático, mecânico e rígido" ${ }^{15}$.

Desse modo, o impulso ou instinto socrático aproximase do Kunsttrieb das abelhas e das aranhas, e da visão dos domos conceituais que aparecem descritos em Sobre verdade e mentira no sentido extra-moral. É uma região limítrofe entre a especialização instintiva e a liberdade de alvos do impulso, o que mostra que uma das facetas da repetição, isto é, do modo como as coisas subsistem na natureza está no próprio modo de articulação das forças, que apenas têm uma aparência de leis, mas que na verdade, como escreve o filósofo, apropriam-se de todas as leis enquanto exercem a própria potência. A menção às forças artísticas da natureza mostra que nelas as tendências instintivas estão a serviço da criação do mundo, e não o inverso. Isso é interessante do ponto de vista analítico, pois é a isso que é conduzida a interpretação, ou seja, a servir como ferramenta para a autotransformação de um indivíduo ciente do caráter indeterminado e desejando ser o criador da própria existência, nos limites possíveis ao mundo humano e à transitoriedade.

\section{O PAPEL DAQUILO QUE RESISTE À SATISFAÇÃO IMEDIATA DO DESEJO}

A vontade de potência não apenas tolera resistência, mas a requer, a deseja, a busca. Se, em Freud, a inibição pode resultar tanto no sucesso do recalque e com isso simbolização, refinamento, ausência de sofrimento e sublimação dos alvos através de deslocamentos satisfatórios, pode também, por

\footnotetext{
${ }^{15}$ ALMEIDA, R. M. Nietzsche e Freud: eterno retorno e compulsão à repetição, p. 176.
} 
outro lado, resultar em algo excessivo, levando à angústia e ao mal-estar. Mas, mesmo aquela sublimação que evita o desprazer psíquico, recebe a ressalva de ser um modo de satisfação bastante tênue se comparado à satisfação direta, que permite descarga plena do impulso. Em Nietzsche a resistência é, pelo contrário, eminentemente lúdica. Ela perpetua o jogo da vida. A própria definição de vida dada nos fragmentos póstumos corrobora essa tese. Para o filósofo da Vontade de potência, a vida é "uma forma duradoura dos processos das fixações de força em que os diversos combatentes crescem desigualmente" (2005a, p. 198). Esse embate é a própria dinâmica vital, onde eventualmente se manda e eventualmente se obedece, e mesmo o obedecer é um comandar a si mesmo, o que é coerente com a visão do masoquismo como um sadismo invertido que aparece na Genealogia da moral, e, aliás, no próprio comandar já está implícita a resistência ao comando: "Obedecer e comandar são formas do jogo da luta" ${ }^{16}$.

Segundo MOURA (2005), já está na estrutura fundamental da Vontade de potência a consideração de uma inibição fundamental: "Digamos que o conceito comporta dois momentos, a própria ambição, que é ambição de potência, e a limitação dessa ambição pela oposição de uma potência determinada, que busca ampliar-se e também ambiciona uma potência maior" ${ }^{17}$. Mas, será que nessa espécie de jogo de oposição e complementaridade entre comandar e obedecer não pode ser pensado em certa medida um masoquismo fundamental, exatamente pela parte de restrição que cabe a todo impulso que ambiciona? Bom, mencione-se

\footnotetext{
${ }^{16}$ NIETZSCHE, F. KSA, 11, Fragmentos póstumos, 36 [22], p. 560.

${ }^{17}$ MOURA, C. A. Nietzsche: Civilização e Cultura, p. 199.
} 
de passagem, era essa exatamente a crítica de Schopenhauer ao querer-viver, no que ele implica de sofrer e fazer sofrer, e por isso também a moral da compaixão. Para Nietzsche, pelo contrário, trata-se de afirmar inclusive a perspectiva do sofrimento, tendo em vista os estados de superação que toda Vontade de poder ambiciona. Esses estados de superação precisam estar por todos os lados e pressupõem a perpetuação do jogo de forças. Nesse caso, a luta seria um sinônimo de cura e, consequentemente, de salvação.

Há um comentário de Lessa da Fonseca (2007) acerca dos Cinco prefácios para cinco livros não escritos que parece seguir a mesma direção. A autora menciona que nessa obra, ao discutir a função da ira no mundo grego, bem como também da sexualidade, da velhice, da morte e da mentira, vê-se a exaltação do conflito, e não há o elogio da vitória ou da derrota, que apenas fixariam hierarquias momentâneas: "No elogio ao combate, à competição, à luta pela doutrina órfica, os impulsos são considerados legítimos" (2007, p. 109). Segundo a leitura da autora, "não se trata de combater a morte, mas de enaltecer a vida, da qual os instintos são inseparáveis" ${ }^{\prime 18}$.

Freud, por sua vez, considera que as possibilidades de satisfação direta ou de sublimação são restritas em face das resistências inconscientes à mudança e da tendência do impulso em repetir estados de satisfação alcançados anteriormente. $\mathrm{O}$ impulso freudiano é eminentemente regressivo: "A pulsão (Trieb) recalcada jamais renuncia à sua completa satisfação, a qual consiste numa experiência primária de satisfação. Todas as formações substitutivas ou reativas, bem como as sublimações, são insuficientes para

\footnotetext{
${ }^{18}$ LESSA DA FONSECA, T. Nietzsche e a auto-superação da crítica, p. 110.
} 
remover sua tensão contínua" ${ }^{19}$.

Desse modo, percebe-se que Freud, num duplo movimento, aceita a ideia de Nietzsche de que a sublimação é um refinamento do alvo pulsional, mas reafirma simultaneamente a ideia schopenhaueriana de que o sofrimento é o fundo de toda a vida, pois a tensão constante do impulso é justamente o fenômeno que nos impele adiante: É da diferença entre o prazer efetivo obtido pela satisfação em relação ao prazer esperado que surge o fator que impele (treibende). Este não permite que o organismo estacione em nenhuma das formas de satisfação anteriormente estabelecidas, mas, ao contrário, fará com que esse organismo, em seu contexto psíquico,reivindique um estado de satisfação profunda, que é, no entanto, impedida tanto pela força das resistências que o processo de recalcamento ainda mantém ativas, quanto pelas dificuldades inerentes ao convívio humano e ao conflito entre desejos e capacidades.

Nietzsche, por sua vez,também considera as resistências, apenas despotencializa a ênfase no sofrimento, entendendo que o impulso deseja o que lhe resiste tanto quanto deseja o seu alvo de satisfação, pois alguma resistência tornaria a satisfação mais prazerosa. Parece um processo de obtenção de prazer que confere um caráter primário ao sadomasoquismo, tendo o prazer como fato originário, um prazer derivado do sentimento de potência, enquanto em Freud ocorre o contrário: o além-do-homem é visto com certo ceticismo e não como possibilidade redentora, pois resulta de uma imposição unilateral que subordina todas as pessoas ao poder de um único homem, o que em termos sociais impli-

\footnotetext{
${ }^{19}$ FREUD, S. Jenseits des Lustprinzips, V, SA, p. 251. Além do Princípio de prazer. Tradução brasileira de Luís Hanns, vol. 2, p. 165.
} 
caria em opressão sexual e, com isto, em massificação e despersonalização.Caso retornássemos a isto, teríamos feito o círculo completo da civilização rumo ao seu princípio na horda primitiva. Isto tudo porque ele se colocou com ceticismo frente às possibilidades do conjunto da Humanidade, no sentido de que não haveria nada que nos anunciasse uma possibilidade de redenção em relação à destrutividade, à vontade de destruição direta, que é própria da dualidade pulsional.

Por outro lado, para Freud, o influxo mútuo entre tendências opostas e autocontraditórias é próprio ao caráter dos impulsos. Os dois modos de atuação da libido, ativo e passivo,afirmativo e negativo, são pensados em termos pulsionais comovida e morte, apoio e limitação recíprocos. No entanto, é inerente à fisiologia dos impulsos a tensão desprazerosa vinculada ao acúmulo de estímulos internos que antecede a tentativa de descarga - se essa descarga, ao ocorrer, implica em afirmação, a possível inadequação dessa possibilidade em relação ao princípio de realidade gerará desprazer psíquico. Há sempre um resto e, portanto, não há plenitude possível para o vivente.

Em Nietzsche, pode-se dizer que ocorre a mesma coisa. Como no caso do mecanismo paralelo da sexualidade descrito por Freud, o prazer de descarga em relação às preliminares, o que é ressaltado pelo filósofo da Vontade de potência é o prazer da afirmação frente ao que resiste ao impulso; isto pressupõe um desprazer, que deverá ser afirmado conjuntamente quase como um requinte associado ao processo de obtenção de satisfação pulsional.A parte mais lúdica da sexualidade, o brincar com as zonas erógenas, pressupõe um prazer suave que atua como que colocando um véu sobre o aspecto desprazeroso da intensi- 
ficação dos estímulos que pressupõe a descarga do orgasmo, o alívio das tensões sexuais.

\section{A BOA NOVA}

Voltando ao além-do-homem em Freud, não há uma possibilidade de transformação da espécie humana como um todo em qualquer outra coisa, excetuando-se a via biológica. Por outro lado, em Nietzsche isto nos parece servir como um motivo para despertar o desejo do leitor de seus escritos pela sua própria reinvenção, isto é, como uma forma de fomentar um querer que se coloque do ponto de vista da superação das atuais condições de existência, sejam elas quais forem. Esse indivíduo seria um leão risonho, tão terrível quanto poético e bem-humorado. Não exatamente o modelo pintado por Freud para o patriarca da horda primitiva quando olhado assim pelo viés do homem como aquele que cria a si mesmo e depois perpetuamente se recria.

Anunciar uma "boa nova" é uma forma poética de articular o desejo rumo a um alvo distante, tal como tentar chegar ao fim do arco-íris. A utopia como isca para a autossuperação.Por exemplo, há em toda a estrutura do Zaratustra uma relação lúdica com a linguagem religiosa e com o modo como essa linguagem conforta e estimula as pessoas rumo à possibilidade de uma vida melhor.Parece que tudo ocorre no âmbito de uma provocação entre o filósofo e cada leitor determinado. De certa forma, podemos pensar que ocorre uma influência, semelhante ao que ocorre na psicanálise, no sentido da recriação da vida e de suas possibilidades. Os bens possíveis para a sociedade partem da transformação no âmbito do indivíduo que constantemente modifica a si mesmo, que vive em revolução 
permanente em torno de novas experiências e novas perspectivas para o pensamento: "Nós vemos como o homem se apequenou" 20 . Este apequenamento de nossa humanidade se dá, em grande medida, pelo recuo diante do sofrimento, isto é, do sofrer pelas coisas que merecem ser sofridas, pois através delas nos recriamos: "No homem, criatura e criador estão unificados" ${ }^{21}$. Parece-nos que a noção de além-dohomem em Nietzsche resgata a ousadia de recriar a sua própria vida. Nesta forma de vivenciar a existência há caos e formação, bigorna e martelo, e, neste sentido, há o reconhecimento da vida no âmbito pulsional, que é onde as coisas precisam ser retificadas. Acredito que é nesse sentido que Nietzsche recusa, através de Zaratustra, a mediania da contemporaneidade e também a brutalidade dos contemporâneos: "Para esses homens de hoje não quero ser luz"! E complementa: "Esses eu quero cegar!" ${ }^{22}$. E quem ele espera que pudesse existir no lugar de seus contemporâneos? Espera por outros homens que aguentem o grande sofrimento produzido pelas grandes escolhas. Uma raça de heróis, no sentido schopenhaueriano, mas não uma matilha de superhomens ou de patriarcas da horda primitiva. Estes últimos não são ainda o além-do-homem nietzschiano.Mesmo sabendo que o comentário de Freud mencionado anteriormente não pretende analisar a filosofia nietzschiana, mas parte de certo modo de um senso comum acerca do conceito de Übermensch, não deixa de ser interessante pensar a coisa toda por este viés criativo - o viés do desejo -tal

\footnotetext{
${ }^{20}$ NIETZSCHE, F. Para Além do bem e do mal. In: Obras Incompletas. Coleção Os Pensadores. Tradução de Rubens Rodrigues Torres Filho, cap. VII, § 225, p. 286.

${ }^{21}$ Idemibidem.

${ }^{22}$ NIETZSCHE, F. Assim falou Zaratustra. In: Obras Incompletas. Coleção Os Pensadores. Tradução de Rubens Rodrigues Torres Filho, quarta parte, § 6, p. 261.
} 
como se dá também na experiência psicanalítica e também pelo viés da psicologia das massas.

Abstract: Freud relates to the notion of beyond-the-man through a double movement, if we consider the direct satisfaction of the Triebe in contrast to the possibility of refining the targets of the drives. On the one hand, the analyst accepts the idea of Nietzsche that sublimation is precisely the means by which occurs the refinement of the targets of the impulses, but simultaneously reaffirms Schopenhauer's idea that suffering is the background of all life, has the constant voltage of the drive is precisely the phenomenon that strains us and propels us forward: it is the difference between the actual pleasure obtained by satisfaction with the expected pleasure that comes the factor that drives (treibende). This does not allow the body to park in any of the previously established forms of satisfaction, but instead will cause this organism in their psychic context, claim a state of profound satisfaction, which is, however, hampered by the force of resistances that the process of repression still keeps active and by the difficulties inherent in human interaction and conflict between desires and capabilities.

Keywords: Desire; drive; will to power; horde.

\section{REFERÊNCIAS}

CACCIOLA, Maria Lúcia Oliveira e Mello. Schopenhauer e a questão do dogmatismo.São Paulo: Editora da USP, 1994.

- A Vontade e a Pulsão em Schopenhauer.In: MOURA, A. H. de. (Org.) As pulsões. São Paulo: Escuta, 1995.

CICERO, M. T. Tusculana e Disputationes. M. Pohlenz. Leipzig: Teubner, 1918.

FONSECA, E. R. Psiquismo e vida - Sobre a noção de Trieb nas obras de Freud, Schopenhauer e Nietzsche.Curitiba: Ed. da UFPR, 2012.

FREUD, S. Das Werk. Berlim: Heptagon Verlag, 2010. Edição digitalizada das obras de Sigmund Freud. 
- Edição Standard Brasileira das Obras Completas de Sigmund Freud, 23 vol. Rio de Janeiro: Imago, 1987. As referências a essa edição são indicadas pelas iniciais ESB, seguidas do número do volume em algarismo romano e do número da página em número arábico.

- Obras Completas. Buenos Ayres: Amorrortu, 1976.

FULGENCIO,L. Kant e as especulações metapsicológicas em Freud. In: Revista Natureza humana, v. 5, n. 1, 2003, pp. 129-173.

LACAN, J. A ética da psicanálise. In: O seminário. Livro 7. Rio de Janeiro: Jorge Zahar, 1994.

LESSA DA FONSECA, T. Nietzsche e a auto-superação da crítica. São Paulo: Humanitas, 2007.

MOURA, C. A. Nietzsche: Civilização e Cultura. São Paulo: Martins Fontes, 2005a.

NIETZSCHE, F. Kritische Studienausgabe. Org. Giorgio Colli e Mazzino Montinari, 15 vols., Munique, DTV/ de Gruyter, 2 ${ }^{a}$ ed., 1999. As referências a essa edição são indicadas pelas iniciais KSA, seguidas do número do volume em algarismo romano e do número da página em número arábico.

- O nascimento da tragédia - ou helenismo e pessimismo.Tradução de J. Guinsburg. São Paulo: Companhia das Letras, 1992.

- Aurora. Tradução de Paulo César de Souza. São Paulo: Companhia das letras, 2004. 
- Obras Incompletas, In: Os pensadores. Tradução de Rubens Rodrigues Torres Filho. São Paulo: Abril Cultural, 1978.

- Assim falou Zaratustra. Tradução de Mário da Silva. Rio de Janeiro: Civilização Brasileira, 2005b.

SHOPENHAUER, A. Sämtliche Werke, ed.Wolfgang Frhr. von Löhneysen, Frankfurt, 1986, 5 vols. As referências a essa edição são indicadas pelas iniciais SW, seguidas do número do volume em algarismo romano e do número da página em número arábico.

- Die Welt als Wille und Vorstellung, [O Mundo Como Vontade e Representação] - 1819 (1 a. Ed.), 1844 (2a. ed.); 1859 (3a. ed). Tradução brasileira de Jair Barboza, São Paulo, UNESP, 2005.

. Die Weltals Willeund Vorstellung, Ergänzungen, [O Mundo Como Vontade e Representação: Complementos] - 1844 (2 a. ed.); 1859 (3a. ed). Metafísica do amor / Metafísica da morte. Tradução de Jair Barboza. São Paulo: Martins Fontes, 2000.

. Über den Willen in der Natur, Sobre a Vontade na Natureza - 1836. 